\title{
Temporal-spatial characteristics of storm surges and rough seas in coastal areas of Mainland China from 2000 to 2019
}

\author{
Yebao Wang ${ }^{1} \cdot$ Jiaqi $\mathrm{Liu}^{2} \cdot \mathrm{Xin} \mathrm{Du}^{1} \cdot$ Qian $\mathrm{Liu}^{1} \cdot \mathrm{Xin} \mathrm{Liu}^{3,4}$ \\ Received: 24 November 2020 / Accepted: 5 February 2021 \\ (c) The Author(s), under exclusive licence to Springer Nature B.V. part of Springer Nature 2021
}

\begin{abstract}
Marine disasters pose a serious threat to economic and social development; therefore, understanding their occurrence rhythms is of great importance to disaster prevention and mitigation. As a major form of marine disaster in China, storm surges and rough seas are particularly worthy of attention. In this study, statistical data regarding storm surges and rough seas over the past 20 years were collected, and a visual approach was utilized to detect their scope, distribution, and temporal-spatial characteristics. Implementation of disaster prevention and mitigation was then discussed. The results revealed the following: (1) storm surges exhibited significant seasonality (occurring in summer and autumn), while rough sea occurrences occurred throughout the year. (2) The losses caused by storm surges showed clear regional differences. Specifically, the economic losses and death tolls in southern provinces were greater than in northern provinces, but they decreased significantly from 2000-2009 to 2010-2019. (3) The loss caused by rough seas also showed regional differences, with greater loss values in the southern provinces than northern provinces. The total loss has dropped significantly in recent years.
\end{abstract}

Keywords Temporal-spatial characteristics $\cdot$ Storm surges $\cdot$ Rough seas $\cdot$ Coastal mainland china

\section{Introduction}

Marine disasters have received much attention in recent decades because they pose serious threats to coastal economies, ecosystems, and human health (Zhou et al. 2018; Adam 2016). Coastal zones are often characterized by high population densities and economic

Yebao Wang

13031613409@163.com

1 School of Ocean, Yantai University, Yantai 264005, China

2 Wenjing College, Yantai University, Yantai 264005, China

3 Key Laboratory of Coastal Environmental Processes and Ecological Remediation, Yantai Institute of Coastal Zone Research, Chinese Academy of Sciences, Yantai 264003, Shandong, People's Republic of China

4 Centre for Ocean Mega-Research of Science, Chinese Academy of Sciences, Yantai 264003, Shandong, People's Republic of China 

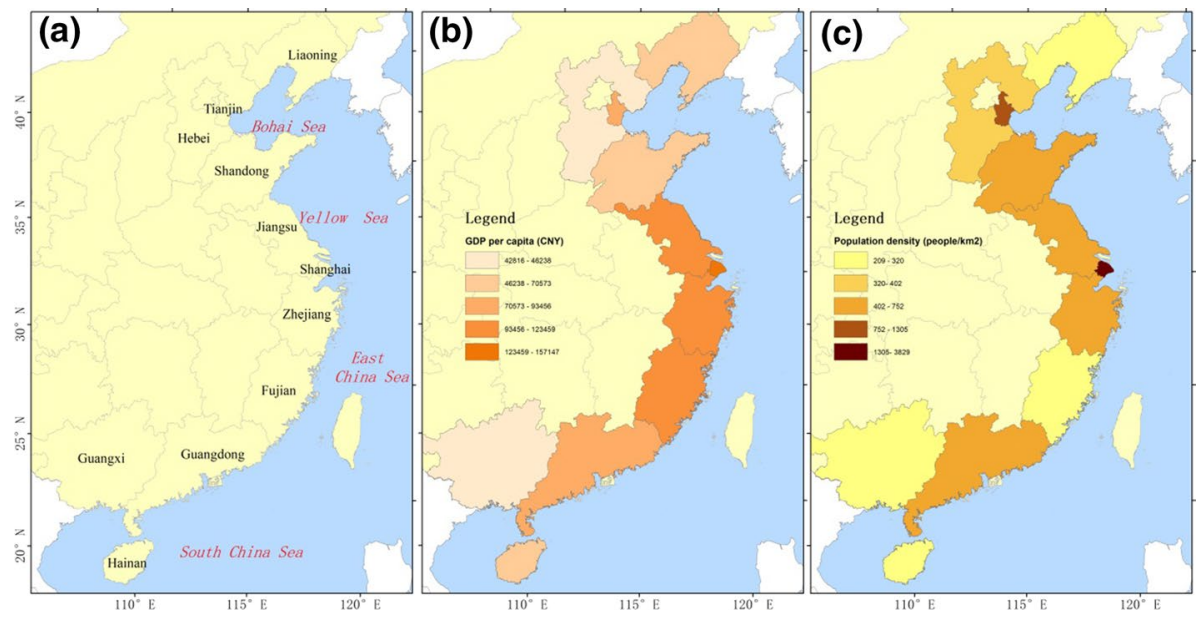

Fig. 1 a Coastal zones and offshore waters of mainland China. b GDP per capita in coastal provinces in 2019. c Population density in coastal provinces in 2019

activities, which make them particularly vulnerable to typical disasters such as storm surges and rough seas (Haran 2020). Currently, preventing marine disasters is an important research topic (Zhao et al. 2019), and developing a deep understanding of disaster characteristics is critical to allowing policy makers to take proper measures when managing marine disasters (Su and Yang 2018). China has traditionally been vulnerable to many natural disasters (Yi 2012). With a continental coastline of $18,000 \mathrm{~km}$ and a total coastal area of nearly 3 million square kilometers, China is among the countries most severely affected by marine disasters (Shi et al. 2020; Fang 2017). The coastal areas of Mainland China (excluding Hong Kong, Macao, and Taiwan) are comprised of 11 provincial-level administrative regions, including two municipalities (Shanghai and Tianjin), one autonomous region (Guangxi), and eight provinces (from north to south: Liaoning, Hebei, Shandong, Jiangsu, Zhejiang, Fujian, Guangdong, and Hainan). The offshore waters are composed of four parts: the Bohai Sea, the Yellow Sea, the East Sea, and the South Sea, which encompass a wide latitudinal range of $4^{\circ} \mathrm{N}$ to $41^{\circ} \mathrm{N}$ (Fig. 1a). Because of their advantageous economic development, coastal regions have become the most developed and populated areas since China's economic reform and opening up in 1978 (Fig. 1b-c). As of 2018, coastal areas of mainland China accounted for about $14.58 \%$ of the total area, but the gross domestic product (GDP) accounted for about $55.13 \%$ of the total. Furthermore, the permanent population of these areas accounted for about $43.63 \%$ of the total area (CSY 2019).

In China, marine hazards mainly include storm surges, rough seas, red tides, green tides, coastal erosion, seawater intrusion, coastal soil salinization, and sea level rise (Cai et al. 2016). All of these have adverse effects on economic and social development. However, except for storm surges and rough seas, few continuous-time and quantitative records are available for these disasters because they have not caused large economic losses and casualties and have therefore drawn less attention from the government. Thus, this study focused on storm surges and rough seas, which are two main causes of casualties and economic losses.

A series of Marine Disaster Bulletins (MDBs) have been issued to the public annually to provide the official statistical information regarding marine disasters (MNR 1989-2019). 
(a)

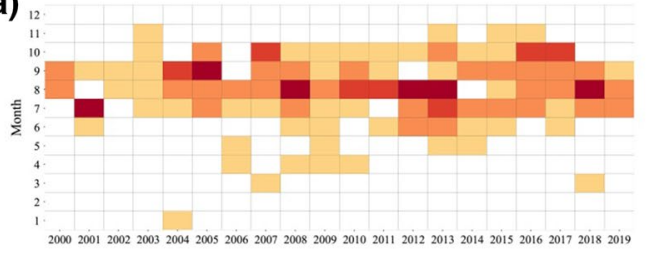

(c)

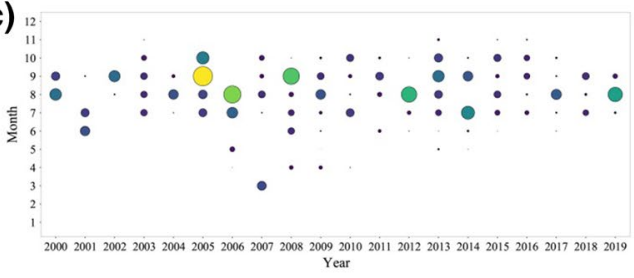

(b)

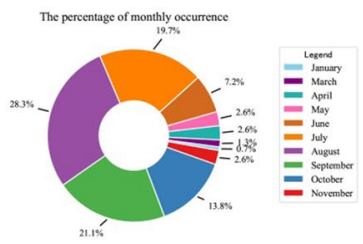

(d)

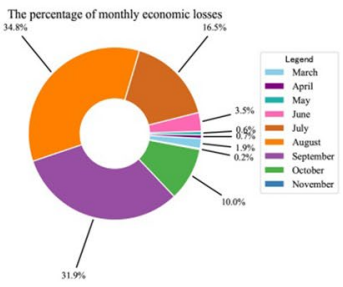

Fig. 2 a Seasonal distribution of storm surge outbreaks. b Seasonal variation of storm surge occurrences. c Seasonal distribution of economic losses caused by storm surges. d Seasonal variation of economic losses caused by storm surges

The data for these were collected by the State Oceanography Bureau (SOA) before 2017 and by the Ministry of Natural Resources (MNR) after 2018 as parts of functions belonging to the SOA were incorporated into the MNR in 2018. First-hand information regarding when, where, and how coastal and marine disasters affect the coastal economy and society at various levels was provided in the MDB; however, some valuable details could not be found in bulletins issued before 2000 for storm surges and rough seas because of the change in statistics and description rules. Hence, only data for the last 20 years were analyzed.

Methods such as data-driven visual analytics facilitate analysis of large amounts of data and provide insights for making informed decisions. Additionally, visual techniques offer the ability to analyze data at multiple levels and dimensions (Raghupathi 2018). The objectives of this study were to review the spatial and temporal characteristics of storm surges and rough seas that occurred in China during 2000-2019. To enhance the identification of relevant messages, a visual approach was used to identify the scope, distribution, and characteristics of storm surges and rough seas occurrences in China. The reasons for their formation were explored, and the status quo regarding management of China's marine disasters and issues existing in China's marine disaster prevention were discussed.

\section{Temporal-spatial characteristics of storm surges}

\subsection{Temporal analysis of storm surges characteristics}

Storm surge events, in China, vary seasonally. As shown in Fig. 2a, over the past 20 years storm surges have occurred in China in all months except for February and December, but most have occurred between April and November. Except for one occurrence in January 2004, the earliest occurrence was in March. The most frequent storm surge event occurred in August, with a total of 43 occurrences accounting for $28.3 \%$ of the total yearly events during 2000-2019. September and July followed, accounting for $21.1 \%$ and $19.7 \%$ of the 


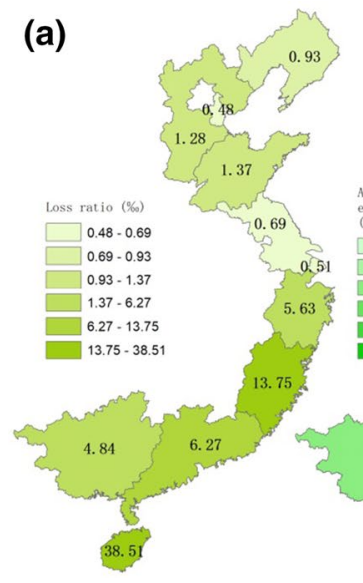

(b)

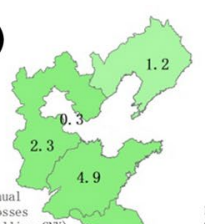

(c)

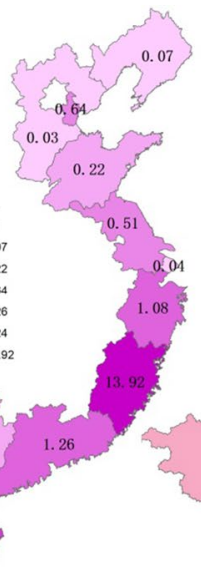

(d)

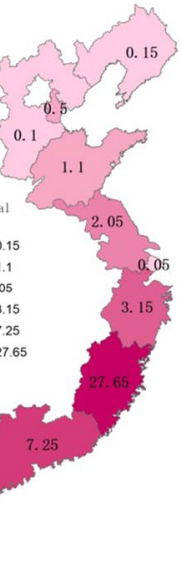

Fig. 3 Direct economic losses and fatalities caused by storm surges from 2000 to 2019 a Economic loss ratio of GDP in each province. b Average annual economic losses between 2000 and 2019 in each coastal province. c Fatalities per million people in each province. d Average annual fatalities between 2000 and 2019 in each coastal province.

occurrences, respectively. April, May, and November had storm surge occurrences of $2.6 \%$, while only $1.32 \%$ of the surges occurred in March (Fig. 2b).

As shown in Fig. 2c, during 2000-2019, storm surge events that caused economic losses usually occurred from May to November. From July to October, economic losses were recorded almost every year, with the greatest economic losses occurring in August, when there was a total of 74.8 billion CNY in damage in the past 20 years, accounting for $34.8 \%$ of the total yearly losses. This was followed by September and July, when $31.9 \%$ and $16.5 \%$ of the total economic losses occurred, respectively. There were no economic losses recorded in January, February, or December (Fig. 2d).

\subsection{Spatial analysis of storm surge characteristics}

At the national level, China is usually impacted by two types of storm surges: extra-tropical-induced storm surges (ETSSs) and typhoon-induced storm surges (TSSs). The ETSSs mainly affect northern coasts, including the Bohai Sea and the northern Yellow Sea, while TSSs mainly affect the southern coasts, including the southern Yellow Sea, the East China Sea, and the South China Sea. Commonly, the destructive power of TSSs is much greater than that of ETSSs, which is consistent with the results shown in Fig. 3. According to the record of economic losses caused by storm surges, the provinces along the East China Sea and the South China Sea (Zhejiang, Fujian, Guangdong, Guangxi, Hainan) have been suffered more serious harm than those along the Bohai Sea and the Yellow Sea (Liaoning, Hebei, Tianjin, Shandong, Jiangsu, Shanghai). A total of 908 deaths caused by storm surges were recorded over the past 20 years, averaging 45.4 fatalities per year. The spatial pattern of total fatalities at national level was found to be similar to that of direct economic losses.

Economic losses and fatalities are highly heterogeneous at the provincial level. Shanghai, which is one of the largest and most important ports in China, reported the highest 

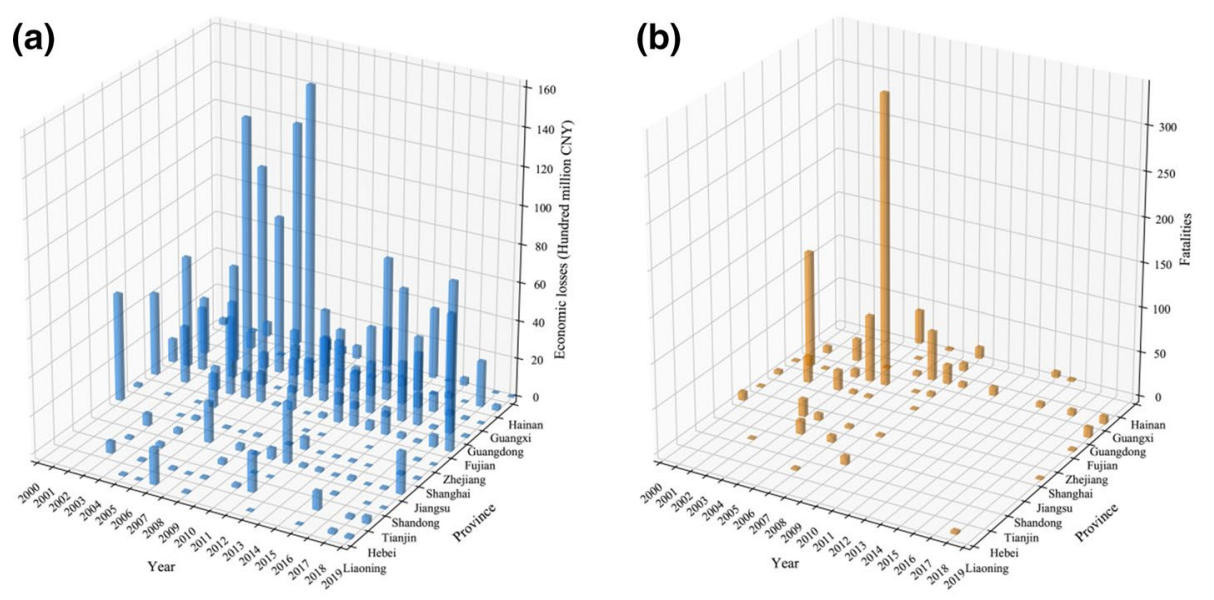

Fig. 4 a Economic losses caused by storm surges in each coastal province during 2000-2019. b Fatalities caused by storm surges in each coastal province

GDP per capita of about 157,000 CNY in 2019 (Fig. 1b). However, storm-related economic losses in Shanghai were lowest except for Tianjin (Fig. 3a, b), mainly because of its high coping and adaptation capacities. In relative terms, Hainan suffered the most severe economic losses, at approximately $3.85 \%$ of its GDP in 2019, followed by Fujian, Guangdong and Zhejiang (Fig. 3a). Guangdong, Zhejiang, Fujian, and Hainan had the highest average annual economic losses (Fig. 3b), with the total losses in these four provinces accounting for $83 \%$ of the total economic losses among all coastal provinces.

Shanghai and Tianjin have the highest population density among all provinces, at 3829 and 1305 people $/ \mathrm{km}^{2}$ in 2019 , respectively. In comparison, the population densities in the other coastal provinces were generally between 210 and 800 people $/ \mathrm{km}^{2}$ (Fig. 1c). Fujian ranked first in both fatalities per million people and average annual fatalities (Fig. 3c, d), which is a large contrast compared with its population density. Fujian, Guangdong, Zhejiang, and Hainan were the provinces that suffered the most storm-related fatalities, accounting for over $90.3 \%$ of the total.

Overall, TSSs have brought much more economic losses than ETSSs in the past 20 years, as reflected by the different loss values in coastal provinces. The losses in southern provinces are obviously greater than those in northern provinces. Furthermore, there has been a rough decrease in economic losses in the southern provinces from 2000 to 2019 (Fig. 4a). Despite a rapid increase in the coastal population in coastal China, fatalities caused by storm surges during 2000-2009 decreased significantly by $93.2 \%$ compared within the period of 2010-2019 (Fig. 4b). The highest death toll was recorded in 2006, when there was 327 fatalities. The worst-hit province was Fujian, which had 553 deaths for the 20 years investigated. 


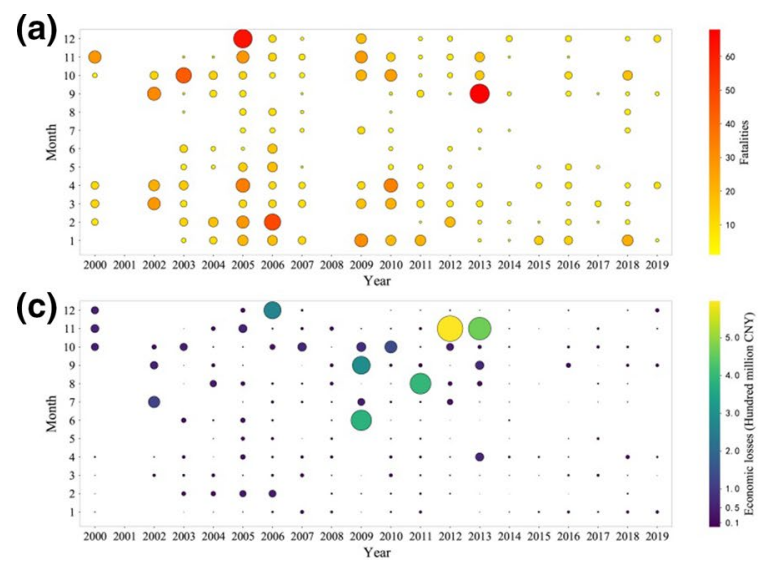

(b)

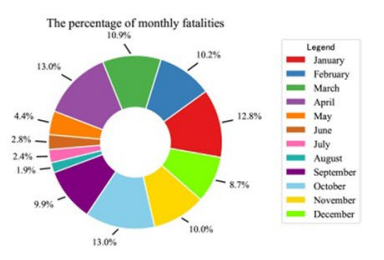

(d)

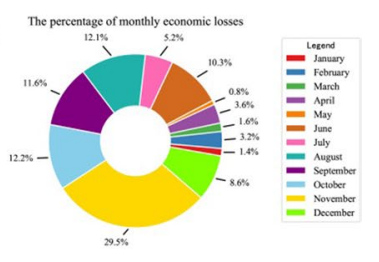

Fig. 5 a Seasonal distribution of fatalities caused by rough seas. b Seasonal variation of fatalities. c Seasonal distribution of economic losses caused by rough seas. $\mathbf{d}$ Seasonal variation of economic losses caused by rough seas

\section{Temporal-spatial characteristics of rough seas}

\subsection{Temporal analysis of rough seas}

Both the records of fatalities and economic losses caused by rough seas are shown in Fig. 5, although death tolls in 2001 and 2008 and economic losses in 2001 were not recorded in the MDBs. Rough sea events in China's coastal waters occurred in all 12 months during the past 20 years. Most fatalities appeared between September and April of the following year (Fig. 5(a)). The highest number of deaths occurred in April and October, accounting for $13 \%$ of the total yearly events, with a total of 383 occurring during 2000-2019. January, March, and February followed, accounting for $12.8 \%, 10.9 \%$, and 10.2\%, respectively. July and June accounted for $2.4 \%$ and $2.8 \%$ of the fatalities, respectively, while only $1.9 \%$ of the fatalities occurred in August (Fig. 5(b)).

As shown in Fig. 5c, rough sea events that caused economic losses occurred in every month during 2000-2019. Events with greater losses occurred in the second half of the year, accounting for $79.2 \%$ of the total yearly losses. The month with the greatest economic losses was November, when a total of nearly 1.24 billion CNY was lost in the past 20 years. The economic losses in November accounted for $29.5 \%$ of the total yearly losses. October and August followed, accounting for $12.2 \%$ and $12.1 \%$ of the totally economic losses, respectively (Fig. 5d).

According to the record of economic losses caused by rough seas, there is little difference between southern provinces and northern provinces at the national level. Overall, 1170 deaths were recorded over the past 20 years, with an average of 58.5 fatalities per year. Southern provinces had more deaths than northern provinces (data from 2004 to 2007 are not included because records were incomplete).

At the provincial level, economic losses and fatalities were found to be highly heterogeneous. Hainan reported the highest loss ratio at about $20.78 \%$, which was followed by Liaoning. Zhejiang's economic losses were also high compared with other regions (Fig. 6a). Hainan, Zhejiang, and Liaoning also had the highest average annual economic losses (Fig. 6b). Economic losses caused by rough seas were not closely related to whether 

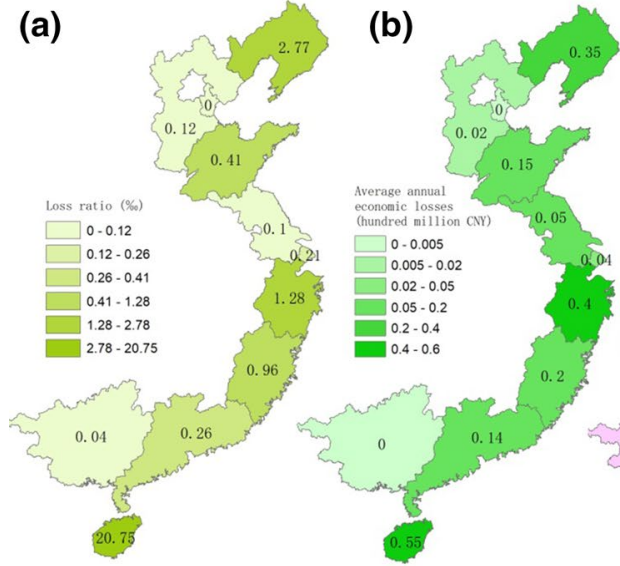

(c)

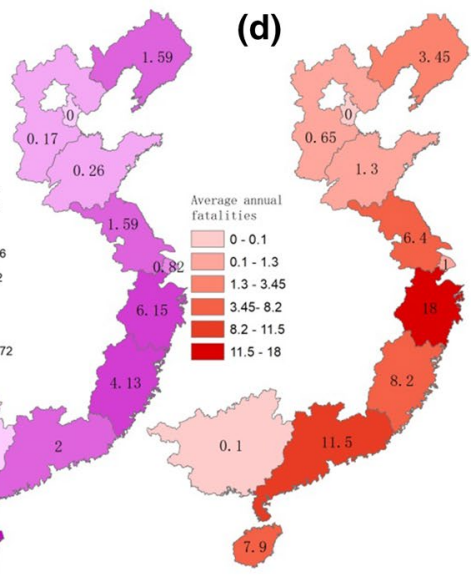

Fig. 6 Direct economic losses and fatalities caused by rough seas from surges in 2000 to 2019. a Direct economic loss ratio of GDP in each province. b Average annual economic losses between 2000 and 2019 in each coastal province. c Fatalities per million people in each province. d Average annual fatalities between 2000 and 2019 in each coastal province

(a)

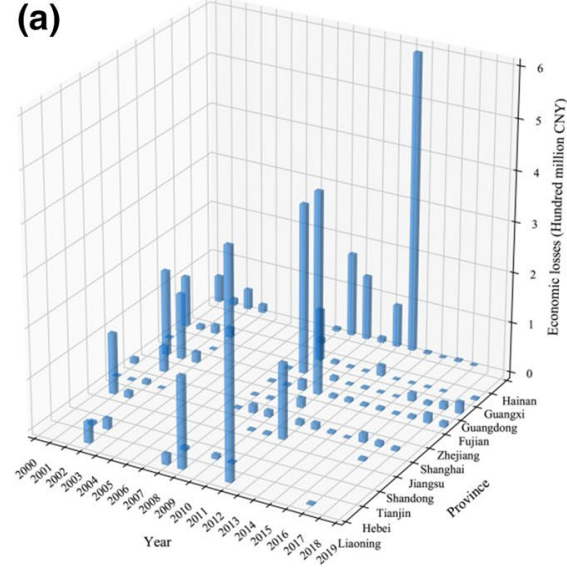

(b)

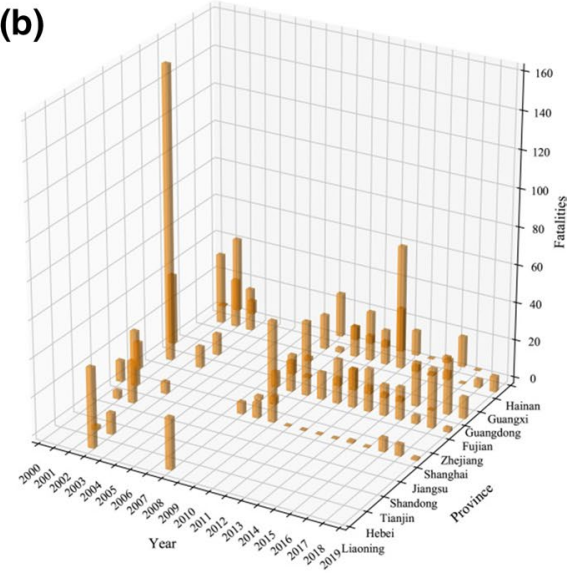

Fig. 7 a Economic losses caused by rough seas in each coastal province during 2000-2019. b Fatalities caused by rough seas in each coastal province (data from 2004 to 2007 are not recorded in MDBs)

provinces were southern or northern. Zhejiang, Guangdong, Fujian, and Hainan were the provinces that suffered the most fatalities, accounting for nearly $80 \%$ of the total (Fig. 6c, d). This phenomenon did not correspond exactly to the distribution of population density.

\subsection{Spatial analysis of rough seas}

Integrating the time and space characteristics in Fig. 7 clearly demonstrated that the economic losses from 2014 to 2019 were significantly lower than those from 2000 to 2013, and southern provinces experienced more economic losses than northern provinces (Fig. 7a). 

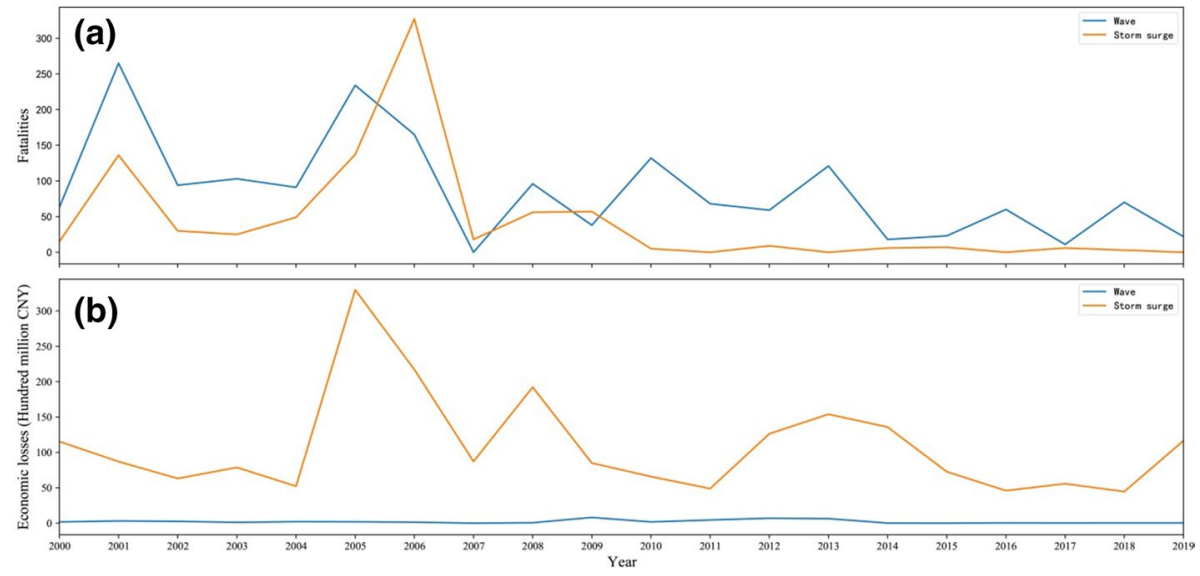

Fig. 8 a Comparison of deaths caused by storm surges and rough seas. b Comparison of economic losses caused by storm surges and rough seas

The highest economic loss of 589 million CNY was recorded in 2013. The worst-hit province was Hainan, where disasters caused 1.102 billion CNY in losses over the 20 years studied. Similarly, fatalities in southern provinces were much higher than in northern provinces (Fig. 7b). The highest death toll was recorded in 2001, when there were 156 fatalities, while the worst-hit province was Zhejiang, where there were 360 deaths during the 20 years investigated.

\section{Discussion}

\subsection{Comparison of fatalities and economic losses caused by storm surges and rough seas}

Among available records, fatalities were only caused by two kinds of marine disasters, storm surges (4376 fatalities) and rough seas (2762 fatalities). However, the distribution of fatalities caused by storm surges in each month was unavailable, so the monthly differences in fatalities between the two hazards could not be compared. Overall, the death toll caused by storm surges was greater than that caused by rough seas (Fig. 8a). Conversely, the economic losses caused by rough seas were greater than those caused by storm surges (Fig. 8b). Additionally, storm surges were found to be the main cause of economic losses, while rough seas were the main cause of death.

In general, exposure to storm surges and waves has increased rapidly because of the great economic growth and population increase in coastal regions globally (Dominicis et al. 2020), including in China (Muis et al., 2016). However, the results showed that while absolute numbers of fatalities decreased, economic losses induced by storm surges and rough seas have generally remained stable. China's efforts toward enhancing the coastal and marine disaster risk management are seen to be the main reason for these positive changes. 
Table 1 Corresponding regulations and industry standards for coastal and marine disasters risk management in China since 2000

\begin{tabular}{ll}
\hline Year & Regulation and industry standards \\
\hline 2005 & Suggestion on Strengthening Marine Disaster Prevention (by SOA) \\
2006 & Regulations Concerning Prevention and Control of Pollution Damage to the \\
& Marine Environment by Marine Construction Projects \\
2006, amended in 2009, 2015 & Storm Surge, Tsunami, Sea Wave and Sea Ice Disaster Contingency Plan \\
2009 & Notice on Further Strengthening the Marine Forecast Disaster Preparedness \\
& and Mitigation (by SOA) \\
2013, amended in 2018 & Provisions on the Management of Marine Disaster Investigation, Assess- \\
& ment and Reporting \\
2014 & Technical directives for disaster prevention and mitigation of storm surge \\
& (GB/T 30,746-2014) \\
2016 & Marine Observation and Forecast, Disaster Prevention and Mitigation \\
& "Thirteenth 5-Year Plan (2016-2020)" \\
2019 & Technical specification for field survey of storm surge and wave disasters \\
& (HY/T 0275-2019) \\
2020 & Terminology of marine disaster prevention and mitigation (GB/T 39,632- \\
& 2020)
\end{tabular}

\subsection{Regional variation}

The economic losses and deaths caused by storm surges and rough seas vary greatly among provinces, and coastal provinces demonstrated various performance at preventing and mitigating disaster risks. Substantial progress in reducing risk and damage has been made in most provinces (Fang, 2017). For example, although Guangdong and Guangxi are geographically similar and are hit by storm surges and rough seas in a similar way, Guangdong showed a larger decrease in terms of annual average fatalities per million people and economic loss ratio of regional GDP than Guangxi. The main reason for this difference is that Guangdong is more economically developed and therefore more financially capable of investing in disaster risk management. These results depict regional differences clearly and indicate the need for considering the heterogeneity of marine disasters and socio-economic development status across coastal regions.

\subsection{Attitudes and strategies for marine disaster prevention and mitigation in China}

The Chinese government attaches great importance to marine disaster prevention and mitigation. As a macro-level policy, the Outline of the Five-Year Plan for National Economic and Social Development is issued regularly. This policy is favorable for the overall implementation of marine disaster prevention and mitigation. In the past 10 years, the goals, tasks, and policies regarding marine disaster prevention and mitigation in the Thirteenth 5-Year Plan (2016-2020) (China State Council 2016) have been further defined compared with those in the Twelfth 5-Year Plan (2011-2015) (China State Council 2011). In addition, a series of regulations and industry standards have been issued by the government to meet the challenges of marine disasters management. Table 1 shows the related documents issued since 2000. In 2006, the "Storm surge, Tsunami, Sea Wave and Sea Ice Disaster Contingency Plan" was released by the SOA. This plan established emergency response 
mechanisms and marine disaster management systems (Shi et al. 2015). To date, China's marine environment governance has gradually formed a policy tool system ( $\mathrm{Yu}$ and $\mathrm{Bi}$ 2019).

Presently, marine disaster prevention and mitigation are regarded as important means to guarantee sustainable development of the economy and society. China has responded to storm surges by establishing engineered defenses (such as seawalls), and the role of seawalls in mitigating loss caused by storms and waves has been addressed by the SOA (Liu et al. 2019). A total of $13,830 \mathrm{~km}$ of such structures had been built as of 2015 , accounting for $40 \%$ of the coastline's total length in China (Luo et al. 2015). Other non-engineering measures such as increasing the capacity of monitoring, forecasting, and generating early warnings by building more tidal observation stations (tide gauges) and using satellite monitoring systems have also been widely adopted in coastal areas.

Additional measures taken by the government include: (1) Strengthening the capacity of monitoring, forecasting, and early warning by building more tidal observation stations (tide gauges) and using satellite monitoring systems (Gu and Tong 2015). (2) Carrying out coastal zone ecosystem protection and restoration project to enhance the capabilities for disaster prevention (Liu et al. 2018). (3) Conducting a marine disaster risk census to identify disaster resistance capabilities of sensitive regions and provide basic information about marine disaster risk as a part of the "National Disaster Comprehensive Risk Census Project." (4) Constructing the Global Ocean Stereo Observation Network to improve ocean observation capabilities comprehensively. The risk of storm surges could be intensified by rising sea levels (Vousdoukas et al. 2018), and the rate of sea level rise around the China Sea has been $3.2 \pm 1.1 \mathrm{~mm} /$ year since 1993 (Qu et al. 2019). However, according to this research, the losses caused by storm surges in China have tended to decrease annually. It could be speculated that the measures taken by the Chinese government have played an important role in disaster reduction.

\subsection{Issues existing in China's marine disaster prevention}

1. Although China has basically built a disaster management system (Zhe et al. 2016), the system related to marine disaster has still not been integrated. Taking ocean observation data as an example, data production is usually derived from the affiliated institutes of the MNR, China Meteorological Administration (CMA), Administration of Ocean and Fisheries (AOF), and some coastal provinces, universities, etc. However, although there have been some related studies (Zhou et al. 2020), a large amount of data is wasted because of their overlap. Accordingly, an integrated management system is still necessary.

2. China is vigorously improving ocean data acquisition capabilities, and a number of databases have been built such as the National Marine Scientific Data Sharing Platform, the National Comprehensive Meteorological Information Sharing System, the Automatic Identification System (AIS) Information Service Platform, and the National Fishing Vessel Dynamic Management System. However, sharing insufficient data and repeated construction results in limited resources, which means the data cannot be fully utilized. Therefore, there is still a great deficiency in comprehensive, high-level, and targeted thematic information sharing systems.

3. There is a lack of standard specifications for service in the field of marine disaster prevention and mitigation, which has greatly increased the difficulty of integrating relevant 
data. Due to the lack of relevant technical support, there is still no information sharing platform for cross-departmental and cross-level marine disaster prevention and mitigation in China.

In view of the insufficient information sharing, decentralized data management, different data standards, and low integration efficiency, it is urgent to establish an information sharing system and mechanism to strongly support marine disaster prevention and mitigation work in China.

\section{Conclusions}

The conclusions based on the data-driven visual analytics conducted in this study can be summarized as follows: (1) storm surges exhibited significant seasonality (occurring in summer and autumn), while rough sea occurrences occurred throughout the year. (2) The losses caused by storm surges and rough seas showed clear regional differences and have gradually declined in China in the past 20 years. (3) This has occurred because China has taken effective measures for preventing and controlling marine disasters, enhanced emergency response capability, and accelerated the pace of research and development (R\&D) activities in this field in the past few decades. Although China is making progress in managing marine disasters, there are still inadequacies in fighting them, including insufficient information sharing, decentralized data management, different data standards, and low integration efficiency. In the future, these weaknesses need to be improved and strengthened purposefully so that the safety of life and property can be ensured.

Acknowledgements We would like to express our gratitude to the editors and reviewers for their helpful comments. We thank LetPub (www.letpub.com) for its linguistic assistance during the preparation of this manuscript.

Author contributions Yebao Wang designed the research, performed the research, analyzed the data, and wrote the paper; all authors discussed the results and revised the manuscript.

Funding This work was supported financially by the Key Deployment Project of the Centre for Ocean Mega-Research of Science, Chinese Academy of Sciences (Grant Number: COMS2019J05) and Startup Foundation of Yantai University (Grant Number: HX19B01).

Data availability The datasets used or analyzed during the current study are available from the corresponding author on reasonable request.

\section{Compliance with ethical standards}

Conflicts of interest The authors declared that they have no conflicts of interest to this work. We declare that we do not have any commercial or associative interest that represents a conflict of interest in connection with the work submitted.

\section{References}

Adam EF, Brown S, Nicholls RJ, Tsimplis M (2016) A systematic assessment of maritime disruptions affecting UK ports, coastal areas and surrounding seas from 1950 to 2014. Nat hazards 83:691-713. https://doi.org/10.1007/s11069-016-2347-4 
Cai R, Tan H, Qi Q (2016) Impacts of and adaptation to inter-decadal marine climate change in coastal China seas[J]. Int J Climatol 36(11):3770-3780. https://doi.org/10.1002/joc.4591

China State Council (2011) Outline of the Twelfth 5-Year Plan for economic and social development (2010-2015)

China State Council (2016) Outline of the Thirteen 5-Year Plan for economic and social development (2016-2020)

CSY. China Statistical Yearbook (2019) China Statistical Publishing House, Beijing 2019

Dominicis MD, Wolf J, Jevrejeva S, Zheng P, Hu Z (2020) Future Interactions Between Sea Level Rise, Tides, and Storm Surges in the World's Largest Urban Area. Geophys Res Lett. https://doi. org/10.1029/2020GL087002

Fang J, Liu W, Yang S, Brown S, Nicholls RJ, Hinkel J, Shi X, Shi P (2017) Spatial-temporal changes of coastal and marine disasters risks and impacts in Mainland China. Ocean Coast Manage 139:125-140. https://doi.org/10.1016/j.ocecoaman.2017.02.003

Gu X, Tong X (2015) Overview of China earth observation satellite programs [space agencies]. IEEE Geosci remote sens magazine 3(3):113-129. https://doi.org/10.1109/MGRS.2015.2467172

Haran NP (2020) Disaster Management in Coastal Areas: An Introduction. In: A. Singh, R.L.S. Fernando, N.P. Haran (eds) Development in Coastal Zones and Disaster Management. Disaster Research and Management Series on the Global South. Palgrave Macmillan, Singapore

Liu L, Xu W, Yue Q, Teng X, Hu H (2018) Problems and countermeasures of coastline protection and utilization in China[J]. Ocean Coast Manage 153:124-130. https://doi.org/10.1016/j.oceco aman.2017.12.016

Liu X, Wang Y, Costanza R, Kubiszewski I, Xu N, Gao Z, Liu M, Geng R, Yuan M (2019) Is China's coastal engineered defences valuable for storm protection? Sci Total Environ 657:103-107. https://doi. org/10.1016/j.scitotenv.2018.11.409

Luo S, Cai F, Liu H, Lei G, Qi H, Su X (2015) Adaptive measures adopted for risk reduction of coastal erosion in the People's Republic of China. Ocean Coast Manag 103:134-145. https://doi.org/10.1016/j. ocecoaman.2014.08.008

MNR (1989-2019) Ministry of Natural Resources: Marine Disaster Bulletin. http://www.mnr.gov.cn/sj/ sjfw/hy/gbgg/zghyzhgb/ (Accessed October 2019)

Muis S, Verlaan M, Winsemius HC, Aerts JCJH, Ward PJ (2016) A global reanalysis of storm surges and extreme sea levels. Nat commun 7(1):1-12. https://doi.org/10.1038/ncomms11969

Qu Y, Jevrejeva S, Jackson LP, Moore JC (2019) Coastal Sea level rise around the China Seas. Global Planet Chang 172:454-463. https://doi.org/10.1016/j.gloplacha.2018.11.005

Raghupathi W, Raghupathi V (2018) An empirical study of chronic diseases in the United States: a visual analytics approach to public health. Int J environl res publ health 15(3):431. https://doi.org/10.3390/ ijerph15030431

Shi X, Liu S, Yang S, Liu Q, Tan J, Guo Z (2015) Spatial-temporal distribution of storm surge damage in the coastal areas of China. Nat Hazards 79(1):237-247. https://doi.org/10.1007/s11069-015-1838-Z

Shi X, Han Z, Fang J, Tan J, Guo Z, Sun Z (2020) Assessment and zonation of storm surge hazards in the coastal areas of China. Nat Hazards 100(1):39-48. https://doi.org/10.1007/s11069-019-03793-Z

Su M, Yang Y (2018) Evolution of district marine policies in China: the case of Shandong Province. Marine Policy 89:124-131. https://doi.org/10.1016/j.marpol.2017.12.028

Vousdoukas MI, Mentaschi L, Voukouvalas E, Verlaan M, Jevrejeva S, Jackson LP, Feyen L (2018) Global probabilistic projections of extreme sea levels show intensification of coastal flood hazard[J]. Nat commun 9(1):1-12. https://doi.org/10.1038/s41467-018-04692-w

Yi L, Ge L, Zhao D, Zhou J, Gao Z (2012) An analysis on disasters management system in China. Nat hazards 60(2):295-309. https://doi.org/10.1007/s11069-011-0011-6

Yu J, Bi W (2019) Evolution of marine environmental governance policy in China. Sustainability 11(18):5076. https://doi.org/10.3390/su11185076

Zhao X, Li H, Ding L, Liu M (2019) Research and application of a hybrid system based on interpolation for forecasting direct economic losses of marine disasters. Int J Disaster Risk Reduct 37:101121. https:// doi.org/10.1016/j.ijdrr.2019.101121

Zhe W, Chan EY, Liu KS, Yeung MPS (2016) The disaster and emergency management system in China. Collaborating centre for Oxford University and CUHK for Disaster and Medical Humanitarian Response (CCOUC), The Chinese University of Hong Kong: Policy Brief

Zhou L, Wu X, Xu Z, Fujita H (2018) Emergency decision making for natural disasters: An overview[J]. Int J Disaster Risk Reduct 27:567-576. https://doi.org/10.1016/j.ijdrr.2017.09.037

Zhou J, He H, Xie X, Xu K (2020) Research on Multi-source Heterogeneous Ocean Data Integration System[C]//Proceedings of the 3rd International Conference on Data Science and Information Technology. 186-192 
Publisher's Note Springer Nature remains neutral with regard to jurisdictional claims in published maps and institutional affiliations. 